\title{
SERTÃO E NARRAÇÃO: Guimarães Rosa, Glauber Rocha e seus desenredos
}

\author{
Pedro Paulo Gomes Pereira*
}

Resumo: Este texto busca verificar as formas de construção da nação em Grande Sertão: veredas, de Guimarães Rosa, e Deus e o Diabo na terra do sol, de Glauber Rocha. Utilizando autores como Homi Bhabha, Stuart Hall, Walter Mignolo, Veena Das, o texto indaga de que forma esses autores construíram o sertão.

Palavras-chave: espaço, nação, sertão, literatura, cinema.

O título deste ensaio se refere diretamente a Nation and Narration, coletânea de artigos organizada por Homi Bhabha, na qual o autor publica o seu conhecido ensaio Dissemination. A referência extrapola a similitude dos nomes e busca abarcar o próprio movimento conceitual do livro, perfazendo jogo lingüístico que pretende indicar o desejo comum de compreender configurações de localidade e temporalidade da nação. ${ }^{1}$

Uma dessas configurações, no Brasil, pode ser localizada numa geografia imaginativa que desenhou uma categoria de espaço, o sertão, como forma principal de falar, definir e delimitar a nação. Entre as diversas narrativas que abordaram e desenharam as intricadas relações entre sertão e nação, Grande sertão: veredas, de Guimarães Rosa, e Deus e o Diabo na terra do sol, de Glauber Rocha, estão

\footnotetext{
* Doutor em Antropologia pela Universidade de Brasília (UnB), pós-doutor pela Universidade de Barcelona, Espanha, professor adjunto da Universidade Federal de São Paulo e professor do Programa de Pós-Graduação em Ciências da Saúde da Unifesp. E-mail: pedro.paulo@, unifesp.br
} 
entre as mais importantes, destacando-se pelo grau de influência no país e pela singularidade de narrar. Este ensaio buscará investigar se e como as obras de Guimarães e de Glauber se inserem no processo de invenção do Brasil, e a existência de vozes que destoam da idéia de uma nação homogênea. Os esforços se concentrarão em averiguar se as maneiras de estruturar o romance e o filme não conduziriam à nova forma de narrar o sertão e, conseqüentemente, de inventar a nação, manifesta nos e propiciada pelos desenredos e interteixos, no emaranhado de vozes que compõem essas obras.

\section{Sertão, nação, narração}

Os termos nação e narração, alocados em justaposição, assinalam a necessidade de se compreender as culturas nacionais como formas de construir sentidos, que influenciam e organizam ações e concepções, constituindo-se numa das principais fontes de identidadeno mundo moderno. As narrações intentam atribuirunidade às imagens da nação como estratégia de construir comunidades imaginadas. As estratégias discursivas se compõem de imagens, panoramas, cenários, e procuram estabelecer uma experiência compartilhada, realçando a idéia de origem comum, de continuidade e de tradição compartida. Apesar de ser construção extremamente singular e recente na história da humanidade - somente no final de século 19 ocorre a autoconceitualização do "estado-nação", conforme analisa Eric Hobsbawm (1990) -, as narrativas localizam origens da nação, do povo e de seu caráter num passado distante e num tempo mítico. Nação, portanto, é uma invenção, uma criação social tecida por narrativas. ${ }^{2}$

A despeito da assunção de unidade, as culturas nacionais não são essencialmente unificadas e homogêneas, tratando-se, antes, de dispositivo discursivo que representa a diferença como unidade ou identidade. As representações, entretanto, não são retilíneas nem 
uniformes e se expressam tanto em narrativas que primam pela preleção descritiva e prescrita da nação una, como naquelas que assinalam a existência da alteridade, elaborando crítica à imaginação da nação como unidade essencial.

No que se refere ao Brasil, o processo de invenção da nação colocou o imperativo de não só transpor modelos europeus e norteamericanos, mas, na empreitada de direcionar os olhares às cores locais, afirmar a autonomia nacional, dirigindo esforços contínuos na busca de símbolos coletivos que possibilitassem certo sentido de pertencimento. A vida do espírito no país se desenvolveria superando a dependência dos moldes estrangeiros e no exercício do mirar reflexivo sobre os exemplos nacionais, surgindo daí o tom geralmente contestador das alegorias nacionais. Existe, contudo, um aspecto importante na construção e aquisição da consciência nacional: o desejo de autonomia se manifestou na consciência de uma elite que necessitava de um conjunto de idéias que justificasse e garantisse sua hegemonia na nação. O processo de emergência dessa elite obliterou vozes, seja pela idealização que imprimia à distância do "outro", seja pelo silenciamento de parcelas expressivas da população ou, ainda, pela intenção de transformação civilizadora. Esta, devendo ser entendida como empreendimento de afirmação da superioridade do Ocidente, pressupõe o desenvolvimento como devir das civilizações "primitivas, bárbaras ou subdesenvolvidas" (ver Mignolo, 2003, p. 168; Dussel, 1995, p. 75). Nesse contexto, a difícil empreitada de pensar o Brasil já se iniciava na escolha de um ponto privilegiado para se falar a nação.

O processo de invenção do Brasil se caracterizou pela proeminência das narrações que destacavam as dimensões espaciais como aquelas que revelariam o mais genuinamente nacional. As narrativas edificaram poderosas imagens de um Brasil construído pelo espaço e as dimensões do espaço e da territorialidade forjadas por essas imagens se constituíram num dos principais fundamentos 
do projeto da nação. Encantada com a imensidão territorial do país ou atormentada pela existência de gigantescos vazios, a imaginação social se voltou para o sertão que, ora como problema a ser resolvido, ora como índice da brasilidade, era conclamado a descrever a história da nação. O sertão tornou-se, então, categoria central no processo de invenção do Brasil. ${ }^{3}$ As narrativas que o tomavam para falar da brasilidade se multiplicaram por diversos meios de expressão. Escritores, cineastas, engenheiros, advogados, médicos, diplomatas e, mais tarde, historiadores, sociólogos, cientistas políticos, se dedicaram a essa tarefa, formando um intricado de narrativas que intentavam formular retratos da nação.

O sertão, em algumas dessas narrativas, se configurou no signo da nação inacabada. A busca de uma homogeneização territorial se deparou com a necessidade de preencher os vazios compreendida como condição da unidade nacional. Essa necessidade de preenchimento ressalta o imperativo da representação horizontal do espaço - que deve ser entendida como devenir na direção da homogeneização e unificação do território nacional. O sertão se tornou, assim, signo da cisão espacial e materializava a divisão da nação; sua existência pressupunha, portanto, um tempo disjuntivo, e justificava, na concepção desses inventores do Brasil, a própria empreitada pedagógica civilizatória das narrações.

Ensejando imagens de vazio, de deserto, o sertão se coloca ora como obstáculo à homogeneização territorial e à eliminação das temporalidades disjuntivas, ora credita-se a ele a identidade nacional. De qualquer maneira, mesmo reconhecendo no sertão o cerne da brasilidade - aquilo que, nesse raciocínio, seria o mais genuíno, pois intocado pelos ares europeus ou norteamericanos-, a sua permanência se devia a uma imaginação civilizadora, preocupada com a alteridade dentro da nação. $\mathrm{O}$ mais significativo repousa na utilização de um "nós", freqüente nas narrativas da nação, que assinala lingüisticamente a presunção de 
uma nação una. Se as características indesejáveis do deserto-sertão devem ser eliminadas e se o sertanejo precisa, ainda assim, persistir como tipo, as narrativas se preocupam, sobretudo, com a premência de submetê-los à construção reformadora das cidades.

As narrações testificam a sua posição quando se constroem numa calculada distância em relação ao sertão. Ao admitir um espaço e tempo diferenciados, se colocam como um outro do sertão, empreitada que pode ser percebida no próprio desejo de dirimir as diferenças, de apaziguar as insurgências, de minimizar as distâncias, de equalizar as temporalidades, de instaurar procedimentos civilizatórios que impliquem obediência aos poderes centralizantes. O sertão deve persistir desde que não irrompa à homogeneização nacional, resultando o ambivalente e simultâneo processo de extingui-lo e de transformá-lo no mito de fundação e de unidade nacional, de trazê-lo como um "nós" arcaico, mas esquecer sua resistência, a sua presença como alteridade.

Se houve uma predominância de narrações que observavam o sertão como um outro Brasil, avesso à civilização e que deveria ser domado, englobado pelas forças centralizadoras - num tempo pedagógico e num espaço horizontal, para utilizar novamente expressões de Bhabha -, outras, porém, inseriam novas dimensões espaço-temporal. ${ }^{4}$ A narrativa da nação deve ser considerada como discurso de autoridade que objetiva uma representação homogeneizadora, porém, esse mesmo processo produz margens que resistem ao discurso unitário, inserindo, inelutavelmente, a dimensão da diferença. É desse lugar de enunciação que surge um tempoespaço performático, no qual as identidades se fazem e refazem, num movimento ininterrupto de diferenciação. Essas margens se insinuam, se contorcem, ressaltando sua presença, possibilitando, por exemplo, a insurgência de utopias - etimologicamente, $u$-topos, outro lugar - que questionam a realidade vivida, como em muitos 
movimentos messiânicos e em comunidades que desafiaram os poderes centrais. ${ }^{5}$

A ambivalência das definições e das concepções surgiria exatamente do confronto com a alteridade, e, dessa forma, o sertão é criado e recriado incessantemente, ora como objeto do desejo, fantasia de um lugar de origem, ora como sítio distante, atrasado, incivilizado (ver Bhabha, 1998). Terra desolada ou paraíso perdido, calcinante e insofrível ou feérico e aprazível, outro Brasil ou rocha viva da nacionalidade, entre outras numerosas construções, o sertão se impôs aos que pensavam a nação.

Imersos nessa intensa e ambivalente relação, a literatura e o cinema se constituíram nos principais meios de expressão na edificação dos alicerces simbólicos da formação nacional. A literatura se estabeleceu como um dos primeiros pilares, sob o qual foram criados símbolos que representavam a identidade nacional, que se transformou em instrumento de investigação e fenômeno central da vida intelectual do país. Assim como a literatura, o cinema também buscou interpretar o Brasil, pesquisando sobre a vida e sobre os problemas brasileiros. Enfim, a ficção, de uma forma geral, se preocupou em conhecer e transformar - construir, edificar - a nação. Por período considerável da história do país, as melhores expressões do pensamento nacional assumiram a forma ficcional. A investigação e reflexão sobre o Brasil se iniciaram com a literatura e com o cinema, e só com a institucionalização das ciências sociais é que os papéis do romancista, do cineasta e do sociólogo começaram a se diferenciar, cedendo lugar à divisão de trabalho intelectual dos dias de hoje. Escritores e cineastas compreendiam o exercício de seus ofícios como missão, em que a arte só se realizava plenamente com presença da cor local e com atitude posicionada diante dos dilemas da nação. Na busca de um representante para o ideal brasileiro, a literatura e o cinema acionaram o sertão para carregar sobre si o símbolo da identidade nacional. ${ }^{6}$ 
Como já se disse, no universo das narrativas que de alguma forma tocaram nas relações entre sertão e narração, Grande sertão: veredas, de Guimarães Rosa, e Deus e o Diabo na terra do sol, de Glauber Rocha, estão entre as que mais se destacaram, radicalizando aspectos muitas vezes apenas tangenciados por outras obras. ${ }^{7}$ Tratase de formas de expressão e de conhecimento, de crítica e de projeto (Bolle, 2004), ${ }^{8}$ que formulam densas indagações sobre as relações entre sertão e nação e, pela primeira vez nas narrativas que abordaram o tema, a construção literária e cinematográfica possibilitou que se fale do sertão sem se recorrer ao arcaico idealizado, e sem o exercício de uma imaginação civilizadora que, por meio de um apelo a um tempo passado compartilhado, edifique imagens de unidade sob as quais se construiria a "identidade nacional".

Para desenvolver essas afirmações devemos enfrentar indagações como: em Grande sertão e Deus e o Diabo os retratos do Brasil sugeririam a disjunção tempo-espacial da nação, distante de propor ou visualizar qualquer totalidade harmônica? Essas obras possibilitam que personagens à margem apareçam no cenário nacional, impondo a sua incômoda diferença? E de que formas as vozes aparecem nessas narrativas?

\section{Desenredos: temas e tradições em Guimarães e Glauber}

Desenredo é nome de um conto do livro Tutaméia, de Guimarães Rosa. O ato de desenredar significa "contar desmanchando", desfazer tramas, perambular por enredos, apresentar o inaudito dos contextos. O termo indica também a interação de temas e tradições, nas quais camadas de ficção se mesclam e desvelam a mistura, formando rede de textos culturais que dialogam entre si. ${ }^{9}$ Em Grande sertão: veredas, os nomes e os vocábulos expressam e constroem o campo intertextual; ${ }^{10}$ os enunciados estão cheios de ecos e de lembranças de outros enunciado, resultado que são de 
outros enunciados. A persistência de metáforas de tramas ${ }^{11}$ indica que a obra de Guimarães se constitui num ponto de intersecção de vozes diversas: o intertextual se sobrepuja ao textual.

Várias películas procuraram dialogar com Guimarães, muitas levando às telas versões filmadas de algumas de suas obras, entre elas: A hora e a vez de Augusto Matraga, de Roberto Santos (1965), Sagarana: o duelo, de Paulo Thiago (1973), Noites do sertão, de Carlos Alberto Prates Correia (1984), A terceira margem do rio, de Nelson Pereira dos Santos (1994), Outras estórias, de Pedro Bial (1999). As dificuldades de transpor a especificidade e a complexidade lingüística de Guimarães para o campo imagético são enormes, e muitas películas acabam por apenas sugerir de longe uma conexão com a obra literária que almejavam adaptar. Dentro do núcleo de filmes que, de uma forma ou outra, buscam estabelecer relações com a literatura de Guimarães, Deus e o Diabo é o que mais radicaliza o diálogo.

A suposição deste texto é a de que Deus e o Diabo seria uma reescrita cinematográfica de Grande sertão. ${ }^{12}$ Glauber não busca elaborar uma adaptação cinematográfica, mas estabelecer diálogo profundo, às vezes consciente e declaradamente manifesto, outras, calcado numa extensa rede - que tem o sertão como tema - que perpassa dos relatos orais, gêneros populares como o cordel, à literatura nacional e internacional. A relação não é causal nem determinista, mas intertextual. O filme de Glauber incorpora as lições e o movimento de Guimarães no plano cinematográfico; a tentativa não é a de adaptar para o cinema a obra de Guimarães, mas de dialogar com ela - reescrevê-la significa reinventá-la. Um dos primeiros aspectos que assinalam esse diálogo está na maneira de construir o sertão.

Existe uma forma de narrar persistente que constrói o sertão de fora: trata-se, nesse caso, de escritores de uma classe média 
citadina que descrevem o "outro" sertanejo. Guimarães e Glauber, contudo, distanciam-se da visão colonizadora que emoldurava o sertão e o sertanejo de fora, tipificando-o. Nesse caso, o escritor era um narrador distanciado, que construía a distância na própria narração em terceira pessoa, conferindo-se o direito de interpretar o longínquo e os modos dos incivilizados sertanejos. No cinema, a linguagem fílmica sugeria a distância da câmera com o outro a que se direcionava. Com intenção de conferir alto grau de verossimilhança, no objetivo de retratar o sertanejo "de verdade", os filmes se estruturavam numa composição que se limitava aos moldes da decupagem clássica, sempre numa linguagem tributária aos moldes europeus e norte-americanos; a distância imposta por tal linguagem separava o narrador de seu objeto, um narrador que "organiza tudo em função de um único olhar, centralizador, que dispõe as figuras com muito cuidado no momento de fazê-las posar diante da objetiva", nos diz Ismail Xavier (1983, p. 133). A distância ensejada no próprio ato de descrever coloca o sertanejo como um Outro, separando-o do Eu civilizado.

Esses procedimentos narrativos, literários ou cinematográficos, se caracterizavam, pois, por sua dimensão monológica. Diferentemente, o ato de desenredar é o que singulariza as obras de Guimarães e Glauber. Deus e o Diabo e Grande sertão apresentam multiplicidade de vozes, de temas, de leituras, de tradições, que elide a figura do narrador onipotente que ostenta seus conhecimentos sobre o sertão. A construção intertextual possibilita que o sertão e o sertanejo não sejam objetos do quais se fala, mas a própria "matéria vertente" (Rosa, 1986, p. 96), e a desconstrução da distância entre o narrador e o narrado se produz na teia dialógica dos discursos.

Diversos são os procedimentos narrativos que garantem às obras de Guimarães e de Glauber a possibilidade de falar o sertão por dentro: elimina-se o narrador centralizador, a utilização de músicas e da musicalidade, do cordel, de vozes populares numa polifonia que 
descentraliza a narração, caracterizando-se pela exploração intensiva da diversidade de vozes, da variedade de tipos de discurso.

Se toda linguagem é dialógica, em Grande sertão e em Deus e o Diabo a construção salienta as vozes constitutivas do discurso, deixando fluir o seu caráter dialógico, que se manifesta na reconstrução da linguagem e nos neologismos de Guimarães, nos travellings e na montagem de Glauber; no infinito movimentarse no espaço e tempo de Glauber; na vinculação de memória e paisagem de Guimarães. Nas obras desses autores, os relatos orais são transfigurados por jogos lingüísticos e imagéticos.

Em Grande sertão, encontramos:

1) arcaísmos como: conspeito, aspeito, prospeito, maximé, consueto, percurar, imigo, militri;

2) infrações gramaticais: "Se despedimos" (p. 68) e "De ouvir ele acrescentar assim..." (p. 391);

3) locuções condenadas pela gramática, mas presentes na fala popular: "quase que" (p. 379) e "enquanto que" (p. $353)$.

4) provérbios alocados em contextos diferenciados, e reelaborados, como nos seguintes exemplos: "Idéia nova que imaginei: que, mesmo pessoa amiga e cortês, virando patrão da gente, vira mais rude e reprovante" ( $p$. 120); "Mocidade. Mas mocidade é tarefa para mais tarde se desmentir" (p. 24); "Quem desconfia, fica sábio" (p. 132); "Mas a água só é limpa é nas cabeceiras" (p. 94) - sobre provérbios, ver Lima (1974).

Aparece, inclusive, alusão a Romãozinho, figura do imaginário popular, principalmente do nordeste de Goiás. Riobaldo - personagem principal de Grande sertão: veredas - aborda a estória da seguinte forma: 
E sei que em cada virada de campo, e debaixo de sombra de cada árvore, está dia e noite um diabo, que não dá movimento, tomando conta. Um que, é o Romãozinho, é um diabo menino, que corre adiante da gente, alumiando com lanterninha, em o meio certo do sono (p. 273).

Essa dimensão intertextual pode ser localizada, também, na existência de tramas de uma obra sendo desenvolvidas pela outra, de temas compartilhados, de apropriação de maneiras de narrar, mesmo que em linguagens tão diferenciadas como a da literatura e a do cinema, como sugere o exemplo a seguir.

A película de Glauber apresenta, nas primeiras imagens, um travelling que mostra uma terra desolada, petrificada. De repente, aparece na tela a figura de uma queixada e de um olho de boi morto já em estado de decomposição. Segundo Durval Muniz de Albuquerque Jr. (2001, p. 281), o filme de Glauber vale-se de imagens-clichê, como as de seca, vaqueiros, gado morto, beatos, que proporcionam campo imagético para a "invenção do Nordeste", entendido como processo pelo qual os discursos constroem a região tendo em comum a estratégia de estereotipização. Dito de outra forma, as cenas iniciais de Deus e o Diabo conformariam esse campo de estereótipos que atuam como efeitos de verdade, trabalhando na invenção do Nordeste e do nordestino. Entretanto, a abordagem de Albuquerque Jr. sobre a película de Glauber se esquece de abordar algumas dimensões importantes, que merecem ser ressaltadas.

No início de Deus e o Diabo, a forma como essas imagens são trabalhadas no filme e como se relacionam em seu interior tornam-se chaves para a compreensão da obra, pois Glauber constrói um sertão que, como em Guimarães, reserva distância do tempo cotidiano e do espaço físico-concreto. É, portanto, com muita ressalva que podemos vincular diretamente sertão e Nordeste em Deus e o Diabo.

A comparação com Guimarães - que Albuquerque Jr. não cita expressamente como um "inventor do Nordeste" - pode esclarecer 
um pouco mais essa questão, pois as primeiras imagens da película dialogam com Grande Sertão. Já no primeiro parágrafo, Riobaldo diz:

- Nonada. Tiros que o senhor ouviu foram de briga de homem não, Deus esteja. (...) Daí, vieram me chamar. Causa dum bezerro: um bezerro branco, erroso, os olhos de nem ser - se viu -; e com máscara de cachorro. Me disseram; eu não quis avistar. Mesmo que, por defeito como nasceu, arrebitado de beiços, esse figurava rindo feito pessoa. Cara de gente, cara de cão: determinaram - era o demo.(...) O senhor tolere, isto é o sertão.

As expressões "bezerro", "olhos", "beiços", "rindo feito pessoa", assinalam bem o campo imagético comum e a busca do diálogo explícito. ${ }^{13}$ A comparação entre essas obras, na tarefa de olhar uma sob a luz que emana da outra, cotejá-las como narrativas que inventaram a nação sob prismas específicos, leva-nos a distanciar de conclusões que consideram que romance e película se edificam sob estereótipos.

Em Grande sertão é sempre muito perigosa a tentativa de circunscrever o sertão a uma região, a uma geografia determinada e delimitada. Apesar de podermos notar locais característicos e mapeáveis, o espaço se torna fugidio, assim como a temporalidade. No que se refere à temporalidade, os documentos comprobatórios de eventos históricos precisos aparecem juntos à forma coloquial “e tantos” (cf. Galvão, 2000, p. 39; ver também 1991). Quanto ao espaço, também temos um procedimento similar. As referências apontam para Goiás, Bahia e, principalmente, Minas Gerais. Em determinado momento, por exemplo, Riobaldo fala de uma vila, localizado-a na fronteira, entre Minas e Bahia: “Aqui é Minas; lá já é a Bahia”. Noutra ocasião: "O São Francisco partiu minha vida em duas partes". Além disso, o Liso do Sussuarão, que Riobaldo define como "o raso do pior havente", pode ser identificado no Raso da Catarina, na Bahia, apresentando características de extrema agrura 
e aspereza, podendo ser comparado, como o faz Walnice Nogueira Galvão (2000, p. 43), ao "deserto onde Lampião se embrenhava com seu bando para escapar ao assédio das forças legais". Portanto, apesar de Galvão afirmar que o sertão de Guimarães não é o do Nordeste, as alusões apontam para a mistura de lugares - geográficos e imaginários - que se sobrepõem, nos quais o sertão não pode ser desconectado daquilo que se entende hoje por Nordeste - sem, evidentemente, ensejar na construção textual quaisquer conotações de estereotipização.

Se a menção a Antônio Conselheiro é evidente na figura de Santo Sebastião em Deus e o Diabo, encontramos também na obra de Guimarães, para continuar citando exemplos da trama desconcertante de eventos, personagens e geografias, Antônio Conselheiro, que aparece na figura do velho "goiano-baiano" Teofrásio, 14 "muito conselhante", "[h]omem no sistema de quasedoido, que falava no tempo do Bom Imperador". Tempo e espaço em Guimarães são alegóricos, metáforas continuadas que se deslocam num processo de des-territorialização. É seguindo esse raciocínio que Wille Bolle (2004) afirma que o sertão rosiano é o resgate de Canudos - coincidindo novamente com a intenção de Glauber. Essa assertiva não significa que o procedimento narrativo de Guimarães seja o de construir uma cópia daquela cidade empírica, mas de uma recriação.

Cabe aqui, ainda, lembramos da cautela sugerida por Antonio Candido (1957, p. 7) sobre os dilemas de geografia em Guimarães. Apesar de sermos capazes de identificar topônimos ao seguir o mapa de Grande sertão, que num primeiro momento parece capaz de ser apreendido pela observação direta, logo descobrimos que o mapa se esfuma, apresentando inusitada composição de lugares, com caminhos irreais e fantásticos. O mapa obedece, em realidade, à necessidade de composição de Guimarães. 
Qual sertão seria esse lugar em que o autor apresenta alegoricamente Canudos e Antônio Conselheiro, e esparge lugares mapeáveis e, simultaneamente, esfuma as referências? É assim, como afirmou Ettorre Finazzi Agrò (1998; ver também 2001) na sua abordagem da obra de Guimarães, que o sertão pode ser pensando como uma dobra deslizando entre significante e significado.

A narrativa de Glauber também abstrai situações e personagens de sua concretude imediata, eliminando a distinção entre o real e o fantástico, dramatizando as ações e retirando-lhes o caráter cotidiano, como se pode observar nos primeiros e últimos planos de Deus e o Diabo. Travellings aéreos sobre o sertão e o mar, reafirmam a distância do tempo cotidiano e do espaço físico-concreto. Reforçase, nesse procedimento narrativo, o caráter imaginativo do espaço. O sertão é geralmente construído como região separada e distante do litoral; ao aproximá-los, Glauber salienta a ambigüidade e indeterminação espacial.

A construção textual e imagética de Guimarães e Glauber, portanto, nos leva a concluir que a noção de espaço é essencial para falar sobre a nação, mas não se confunde imediatamente com qualquer região específica. Daí não se poder enquadrar direta e imediatamente, ao contrário do que assinalam algumas críticas, esses autores no regionalismo. No que diz respeito à abordagem de Albuquerque Jr. sobre Glauber, fica fácil se constatar - depois de compararmos Deus e o Diabo e Grande sertão, apreendendo os elementos de intertextualidade - o quanto o cineasta se distancia de qualquer discurso estereotipado.

\section{Interteixo: tecendo tramas}

Desenredo se aproxima semanticamente de outro termo de Guimarães: interteixo, que se refere à atividade de tecer e entrelaçar. ${ }^{15}$ Grande sertão e Deus e o Diabo abordam temas similares, falando 
do cangaço, de jagunços e da religiosidade popular. Guimarães coloca musicalidade na fala sertaneja, construindo frases com cadência, com aliterações que expressam ruídos e movimentos de animais, e até rimas. Glauber também trabalha essa musicalidade, seja utilizando o cordel para estruturar a narrativa, seja pela própria construção dos diálogos no filme.

Em Guimarães, a sintaxe e os neologismos modulam a fala sertaneja. Ele utiliza várias formas de neologismo: superpondo e assimilando vocábulos homófonos (como, por exemplo, "vorara": associação de devorar, de voragem, voraz; ou "serepente": ser que de repente se transforma em serpente); usando substantivos como verbos ("miasmava", "asmava", "erisipelava"); verbos como adjetivos ("um rôo de remorso"); entre outros. Há também alteração da sintaxe, que se processa de tal forma que torna as frases com sentido equívoco: "É preciso de Deus existir a gente, mais; e do diabo divertir a gente com a sua dele nenhuma existência".

A decupagem e a encenação glauberiana, por sua vez, formam uma tessitura de vozes que se mesclam, e possibilitam que o estranhamento não se localize nalgum ponto fora da narrativa. $\mathrm{O}$ texto prima pela textura descontínua, pela alteração espaço-temporal, pela variação do tom, pela aproximação constante entre a narração e as características dos personagens. O cordel acentua o caráter de oralidade do filme.

A narração se origina e se reforça na palavra de um cantador popular, que desempenha o papel de alinhavar as partes principais e conduzir o filme. A música inicia a história, ambientando os personagens, entrevendo e adiantando os acontecimentos:

Manuel e Rosa viviam no sertão

Trabalhando a terra com as próprias mão

Até que um dia, pelo sim, pelo não, Entrou na vida deles o Santo Sebastião. 
Trazia bondade nos olhos,

Jesus Cristo no coração. ${ }^{16}$

Cego Júlio sobe a escadaria de Monte Santo e se depara com Antônio das Mortes, que lhe informa ter matado a todos e que só deixara dois para contar história. Manuel e Rosa aparecem no meio da caatinga. A música sublinha a situação.

Da morte de Monte Santo

Sobrou Manuel Vaqueiro

Por piedade de Antônio

Matador de cangaceiro.

A canção anunciará o encontro de Manuel e Rosa com Corisco:

Mas a estória continua

Preste mais atenção:

Andou Manuel e Rosa

Nas veredas do sertão

Até que um dia, pelo sim, pelo não

Entrou na vida deles

Corisco, Diabo de Lampião.

Antônio das Mortes correndo, movimentando-se de um lado para outro. Corisco aparece em vários lugares ao mesmo tempo. Antônio das Mortes pula na frente de Corisco e grita: "se entrega Corisco". O cangaceiro salta rapidamente. Antônio das Mortes se atira. Corisco gira, e cai gritando: "Mais forte são os poderes do povo!". Corisco morto, Dadá baleada. Antônio das Mortes aproxima-se com um facão nas mãos. Surgem na tela Manuel e Rosa, correndo pelo sertão. A música no fundo vai concluindo a história:

O sertão vai virar mar,

E o mar vai virar sertão!

Tá contada minha estória, 
Verdade, imaginação.

Espero que o sinhô tenha tirado uma lição:

Que assim mal dividido

Esse mundo anda errado,

Que a terra é do homem,

Não é de Deus nem do Diabo!

Essa citação aleatória de trechos das canções populares do filme de Glauber deve-se à sua importância na composição geral da película, já que sinaliza como elas estruturam a obra. Contudo, dialogando com as canções populares, a música de Heitor VillaLobos, interagindo com as imagens, acaba por conferir novas dimensões às cenas. ${ }^{17}$ Deus e o Diabo se inicia com tomadas aéreas, tendo no fundo $A$ canção do sertão, ária das Bachianas brasileiras $n^{\circ}$ 2. Depois de matar o coronel Moraes, Manuel foge, a câmera o acompanha e a Dança das bachianas brasileiras $n^{\circ} 2$ acentua a dramaticidade da situação, atuando diretamente na composição imagética. Magnificat alleluia realça a voz de Sebastião. A subida de Manuel ao Monte Santo é avivada pela Cantiga, ária das Bachianas brasileiras $n^{\circ} 4$. Tanto a conversão de Manuel a Santo Sebastião como a Corisco são marcadas pela música Canto do sertão, coral das Bachianas brasileiras $n^{\circ} 4$. Depois das violentas imagens na escadaria, quando Antônio das Mortes aparece em diversos lugares, atirando contra os beatos, a câmara nos apresenta os mortos, com o Magnificat alleluia ao fundo. Outra passagem, Miudinho, dança das Bachianas brasileiras $n^{\circ} 4$, ressalta a tensão da cena, conferindo tom trágico a Antônio das Mortes. Na descida aos infernos, o Magnificat alleluia e Quarteto $n^{\circ} 11$ - allegro non troppo compõem a cena. Quando cego Júlio chega ao acampamento de Corisco, para avisá-lo que Antônio das Mortes estava em seu encalço, a Canção sertaneja, prelúdio das Bachianas brasileiras $n^{\circ}$ 2, sublinha a reação do personagem. A cena de amor entre Corisco e Rosa dá-se sob o som da Cantilena, ária das Bachianas brasileiras $n^{\circ} 5$. No final, na corrida desesperada de Manuel e Rosa, a canção de Sérgio Ricardo cede para o Chorus $n^{\circ} 10$. 
A canção - as trovas populares do cordel - e a música de Villa-Lobos aderem à estrutura do filme, e acentuam-lhe o caráter de drama. Esse mesmo procedimento narrativo marca Grande sertão. Riobaldo acredita que a sua vida já estava dita numa canção.

Urubu é vila alta,

Mais idosa do sertão:

Padroeira, minha vida -

Vim de lá, volto mais não?...

Corro os dias nesses verdes,

Meu boi mocho baetão:

Buriti - água azulada,

Carnaúba - sal do chão...

Remanso de rio largo,

Viola da solidão:

Quando vou p'ra dar batalha,

Convido meu coração... (p. 114-115)

A Canção de Siruiz resume o próprio livro, adiantando os acontecimentos, alinhavando e condensando os temas principais. Foi Davi Arrigucci Jr. um dos primeiros a observar a importância dessa canção. Para ele (1994, p. 27), trata-se de uma forma híbrida, que mescla a narração épica e lirismo, e desvela, de forma cifrada e enigmática, o destino de Riobaldo. Assim, é a poesia oral que proporciona o desenrolar da história e Grande sertão termina por ser delineado por essa canção.

Todo o romance, portanto, seria uma tentativa de esclarecer o enigma que essa balada enseja. ${ }^{18}$ Ao colocar a Canção de Siruiz no centro da narrativa, Guimarães afirma o seu projeto de explorar as aproximações com a oralidade, a ponto de alguns críticos argumentarem que existe mesmo uma reinvenção da fala sertaneja. Tudo se passa como se a narrativa em Grande sertão buscasse tornar imperceptíveis os limites entre o oral e a escrita. 
As camadas intertextuais são ainda mais densas. Walnice Nogueira Galvão (2000), por exemplo, lembra-nos da importância da versão portuguesa de uma novela de cavalaria francesa: História do Imperador Carlos Magno e dos doze pares de França. Esse livro propiciou grande quantidade de cantigas, peças de cordel, e influenciou inclusive no processo de nominação de pessoas em diversas regiões do Brasil. Os episódios eram lidos em voz alta nas casas para os familiares e próximos. Essa obra aparece em diversos momentos em Grande sertão: Riobaldo se imagina "Gui de Borgonha", amado da princesa Floripes e herói da novela; Ricardão, um dos traidores na obra de Guimarães, é designado de Almirante Balão; Joca Ramiro é denominado de "par-de-frança" (Galvão, 2000, p. 38).

A busca de construir uma narrativa que não expressasse unicamente a perspectiva do homem culto da cidade sobre o sertão marca a literatura de Guimarães e pode ser notada já no conto "Minha gente", em Sagarana. Nele, Guimarães aborda o contraste entre os saberes do sertanejo e o do doutor da cidade que, apesar de conhecer algumas coisas, outras ele ainda tinha que aprender. Desenhando um caso de amor numa fazenda do sertão, Guimarães concebe o homem urbano como aquele que deve aprender, deve passar por um processo de aprendizagem. O narrador não discorre sua sapiência aos incautos, mas, antes de tudo, se coloca na posição daquele que tem de se instruir com o sertão. A postura de busca de diálogo, como já se disse, será um dos pilares de Grande sertão.

Riobaldo, o grande "Cerzidor", narra as suas histórias, fazendo-nos percorrer suas veredas, compartindo sua memória. Mas, o aparente monólogo é, em realidade, diálogo com interlocutor desconhecido; interlocutor evocado, mas a quem não se dá diretamente a palavra, somente as falas de Riobaldo aparecendo. Contudo, a aparente ausência de enunciação do interlocutor se desmonta quando percebemos que existe altercação de idéias. O 
diálogo se constrói a despeito da inexistência de frases daquele com quem Riobaldo conversa. Essa forma de narrar imprime caráter enigmático à narrativa. $\mathrm{O}$ diálogo - ou quase diálogo, pois o seu interlocutor não aparece inteiramente - força o personagem a se expor, a ser enfático, a se posicionar. Esse monólogo-diálogo proporciona relação de mútuo transformar, e indica a instabilidade da narração e do narrador Riobaldo. ${ }^{19}$

A introdução do cordel ou do monólogo-diálogo por si não garante os efeitos conseguidos em Deus e o Diabo e Grande sertão. Ismail Xavier cita um exemplo significativo no que tange ao cinema: A grande feira, filme de Roberto Pires. Esta película compõe sua narrativa, apresentando-nos um poeta popular que lê para uma audiência na rua a história que o espectador acompanha na tela; todavia, constata Xavier (1983, p. 143), a relação entre a voz do poeta e a história não incide sobre a organização das imagens. Em Deus e o Diabo, ao contrário, o cordel e a estrutura textual formam um todo único; e, da mesma maneira, o monólogo/diálogo da obra de Guimarães estrutura o romance.

Voltando a Guimarães, podemos constatar que há um descentramento produzido pelo diálogo de Riobaldo com o interlocutor que nunca aparece diretamente, mas que amiúde intervém, já que a narração demonstra que existe um contraste entre as idéias do narrador e do seu interlocutor. As frases " $A$ h, mas falo falso. O senhor sente? Desmente?” (p. 175) sugerem que a história riobaldiana destoa do pensamento crítico e do olhar sóbrio daquele com quem dialoga. Essas vozes e o efeito de descentramento proporcionam um diálogo e fazem com que o próprio ser de Riobaldo seja continuamente (re)construído. Riobaldo diz: "o senhor me ouve, pensa e repensa, e rediz, então me ajuda" (p. 82); "com o senhor mesmo - me escutando com devoção assim - é que aos poucos vou indo aprendendo a contar corrigido" (p. 83); "Mais hoje, mais amanhã, quer ver que o senhor põe uma resposta. Assim o senhor 
já me compraz. Agora, pelo jeito de ficar calado alto, eu vejo que o senhor me divulga" (p. 86); "O senhor me organiza” (p. 277); "Sua alta opinião compõe minha valia" (p. 11). O próprio Riobaldo solicita a intervenção de seu interlocutor - "Conto ao senhor é o que sei e o que o senhor não sabe; mas principal quero contar é que eu não sei se sei e que pode ser que o senhor saiba” (p. 89) -; a intercessão produz a atualização do contar, pois a memória nunca é a repetição do acontecido.

A lembrança da vida da gente se guarda em trechos diversos, cada um com seu signo e sentimento, uns com os outros acho que não se misturam. Contar seguido alinhavado, só mesmo coisa de rara importância. De cada vivimento que eu real tive, de alegria forte ou pesar, cada vez daquela hoje vejo que eu era como se fosse diferente pessoa. Sucedido desgovernado. Assim eu acho, assim é que eu conto. $\mathrm{O}$ senhor é bondoso de me ouvir. Tem horas antigas que ficaram muito mais perto da gente do que outras, de recentes datas. O senhor mesmo sabe. (p. 99).

Walter Benjamin (1980) dizia existirem duas formas de memória. Uma que se refere simplesmente às recordações e faz do gesto de lembrar algo mecânico e racional; a outra, se vincula ao rememorar emotivo, anterior à fragmentação da cultura e do sujeito, estreitamente ligada à narratividade oral. Esse caráter de oralidade está impresso nas memórias riobaldianas, e possibilita um rememorar emotivo, fazendo com que o fluxo da memória se teça na procura da construção dum passado.

Embora Deus e o Diabo privilegie a "ação"-os acontecimentos surgem na tela sempre na perspectiva do futuro e são poucos os momentos de erupção direta da lembrança, procedimento narrativo que, de certa forma, aproximá-lo-ia mais de Os sertões, indicando uma interlocução também com Euclides da Cunha (1985) -, no filme, o descentramento do discurso deve-se a diversos procedimentos narrativos: Glauber ora adere o olhar da câmara aos personagens, nos momentos em que narrador e personagem se identificam, ora 
utiliza ponto de vista distanciado, por exemplo, quando a narração se concentra num cantador, que usa o pretérito para se referir às aventuras dos personagens. As narrações configuram as personagens e expõem as suas emoções e sensações (cf. Xavier, 1983).

A linguagem cinematográfica, em Glauber, se afasta da pura descrição. As seqüências em que Manuel, depois de matar seu Moraes, é perseguido por jagunços exemplificam bem essa tentativa. Ao invés de as personagens aparecerem numa seqüência descritiva clássica - como é do estilo do faroeste norte-americano - elas se dispõem numa seqüência emocional. A rapidez da ação expressa na tela corresponde à violência da sensação de Manuel sendo perseguido. A movimentação da câmera, os enquadramentos diferenciados, a montagem que, como num mosaico, trabalha cenas muito díspares dotando-as de sentido, fazem com que linguagem e personagem se mesclem profundamente.

As duas obras, portanto, transitam entre gêneros primários e secundários (Bakhtin 1997), utilizando tramas em que os gêneros discursivos da oralidade (o cordel, a fala, a poesia e a música populares) são interpretados pelo gênero literário e cinematográfico. Existe mesmo um embaralhamento ocasionado pela multiplicidade de redes discursivas provenientes das relações entre os gêneros do discurso.

Uma das dimensões em que mais claramente se evidencia o diálogo existente entre Grande sertão e Deus e o Diabo é a religiosa. A presença de elementos religiosos como estrutura fundamental na constituição do sertão é constante no cinema e na literatura do Brasil. Guimarães Rosa, Euclides da Cunha, José Lins do Rego, na literatura; Lima Barreto, Nelson Pereira dos Santos, Anselmo Duarte, no cinema. Esses escritores e cineastas descreveram o sertão priorizando o campo simbólico-religioso, o que de certa maneira nos leva a pensar na analogia entre o deserto e sertão. O deserto, como 
símbolo purificador, sempre exerceu forte influência no pensamento cristão, bastando lembrar, para exemplificar essa afirmação, que Jesus foi para o deserto enfrentar a solidão e a tentação, como forma de se purificar. O sertão está sob o mesmo complexo simbólico; seu apelo é similar ao do deserto, e remete àquelas áreas que Arnold Van Gennep (1978) definiu como lugar situado entre dois territórios.

$\mathrm{Na}$ rede intertextual edificada por essas obras, a forma como a esfera religiosa as caracteriza talvez seja o mais expressivo ponto de comunicação. Ao colocar no centro do filme a ambigüidade, a travessia, o contato com elementos do campo simbólico-religioso, Glauber dialoga diretamente com a obra de Guimarães, o que indicaria que esses autores acessaram um mesmo códice, que se desmancha em redes intertextuais..$^{20}$ Essas obras estão, pois, em diálogo profundo entre si e entre gêneros primários e secundários, revelando-nos certa maneira persistente de construir e de se relacionar com o sagrado, que se manifesta numa simbólica do mal - não será à toa, por exemplo, que os momentos cruciais de Deus e o Diabo e Grande sertão: veredas serão denominados de "descida nas inferneiras" e "descida ao inferno", respectivamente.

\section{Diferido: a construção de alteridades}

"Por causa que o outro era diferido, composto em outra séria qualidade de preocupações", afirma a certa altura Riobaldo (p. 386). Diferir indica tanto a preocupação com a especificidade do outro, a inquietação com a diferente, como a apreensão com o diferimento no sentido de adiar, retardar, procrastinar. Essa dimensão nos conduz a expandir os questionamentos - direcionando-os, evidentemente, também à obra de Glauber. A película e o romance evocam o sertão como forma de falar o Brasil, então, é razoável indagar se as imagens e as noções utilizadas nessa rede intertextual, nesse emaranhar de desenredos e interteixos, construiriam o Brasil 
como um sistema integral, que abarcaria e reduziria justamente a alteridade e o diferimento. Se isso fosse verdade, o diálogo seria somente superficial, pois ao contrário de sugerir o diferente, composto de "outra séria qualidade de preocupações", terminaria por menoscabar o outro.

Essa preocupação com o diferido nos conduz às perguntas formuladas no início deste texto, que procuravam averiguar se existiria nesses autores um apelo ao sertão arcaico como forma de evocação de um passado compartido - que possibilita imagens de identificação num passado comum compartilhado e numa origem única -, mas que deveria ser superada pelas forças modernizadoras e civilizacionais. Enfim, vale repetir, a invenção do Brasil se ancoraria nas imagens do sertão como metáfora da visibilidade do devir da nação una e homogênea?

Rubem Fonseca (1994, p. 461 e 468), por exemplo, expressa na fala de um personagem, em Intestino grosso, as seguintes idéias:

(...) os caras que editavam os livros, os suplementos literários, os jornais de letras. Eles queriam os negrinhos do pastoreio, os guaranis, os sertões da vida. (...) Eu não tenho nada a ver com Guimarães Rosa, estou escrevendo sobre pessoas empilhadas na cidade (...) Não dá mais para Diadorim.

Certamente, essa afirmação acaba por enquadrar Guimarães num tipo de narrativa de identidade da nação, alicerçada no sertão como mito da brasilidade. Esses mitos, por sua vez, desconectados e incompatíveis com a vida urbana, têm o efeito de produzir a visão da nação como entidade totalizadora, que engloba a diversidade numa grande unidade, representada na expressão que Bhabha (1998) definiu como todos como um. Nessa concepção, não seria difícil de alocar a prosa de Guimarães e sua reescrita cinematográfica em Glauber como narrativas primordialistas que criam o sertão como mito de um passado compartido, estabelecendo a construção de uma identidade como forma de manter o controle, por meio do 
esquecimento, da violência da origem da nação. Contudo, como se observou no decorrer deste texto, os desenredos e interteixos apontam justamente para a heretogeneidade da nação e, na medida em que tecem e tramam uma composição de vozes, colocam em evidência suas fissuras e disjunções, ressaltando suas diferenças - o diferido.

A análise que venho desenvolvendo parece mesmo indicar que o interessante das obras de Guimarães e de Glauber repousa na tematização da própria alteridade, que a frase com a qual iniciei este tópico exemplifica bem. A importância com o diferido se deve, na minha perspectiva, à composição das vozes nessas obras, ao arranjo intertextual - daí a necessidade que tive de me deter nos desenredos e interteixos, como metáforas do caráter eminentemente intertextual de Grande sertão e Deus e o Diabo. Tanto no filme como no romance, o diálogo entre textos e tradições permite que personagens à margem, como Manuel e Riobaldo, que comumente se apresentavam pela benevolência de cineastas e literatos, e sempre do prisma destes, se manifestem numa pluralidade de vozes. Os discursos se interpenetram, as falas partem de múltiplos registros e, desse modo, a construção textual e imagética faz com que interajam a fala e a imaginação dos sertanejos sobre eles mesmos, a visão do sertanejo sobre as cidades e a maneira como os citadinos vêem o sertão.

Ao estruturar o romance como uma conversa, Guimarães dispõe no centro da narrativa a questão, evitada por muitos escritores e cientistas sociais, da heterogeneidade da nação (cf. Bolle, 2004, p. 39-40). A conversa entre o sertanejo Riobaldo - que foi jagunço e depois se transformou em fazendeiro - e o doutor da cidade coloca em evidência as diferenças, os conflitos - como também sublinha a tentativa de mediação e diálogo. Já Glauber nos apresenta uma composição imagética que revela a heterogeneidade da nação não só pelos personagens que se situam em classes sociais específicas 
e nos conflitos entre essas classes, mas por que o filme proporciona o diálogo entre as imagens, a voz de um poeta popular, a música erudita de Villa Lobos, a poesia, os mitos e as histórias do povo.

Contra certa perspectiva - comum na literatura e na cinematografia nacional - que constrói o sertanejo e o sertão a partir de uma distância denunciada pelo próprio discurso, essas obras arquitetam uma rede intertextual que descentraliza a narrativa. No caso de Guimarães e Glauber, a intertextualidade desautoriza a redução etnocêntrica que localiza no sertão traços arcaicos que se deve superar e que identifica o sertanejo como figura de pensamento irracional. O sertão, assim, é construído de dentro. Os temas, as canções, as poesias, as vozes perpassam essas obras, que se comunicam entre si e com outras obras literárias e cinematográficas, e dialogam diretamente com diversas construções e formas de narração populares.

O sertão - o cangaço, o messianismo, as revoltas populares, a religião do sertanejo - se apresenta por meio de experiências que surgem à margem da nação; e como forma de se pensar o Brasil justamente por refletir sobre a irrupção de outros tempos e espaços. Nos dois autores, trata-se de pensar entre tradições, alocando às configurações espaciais diferentes histórias.

O sertão, povoado de cangaceiros, jagunços, líderes messiânicos, coronéis, matadores de cangaceiros, alegoriza as comunidades que lutaram contra os poderes centralizantes (como Canudos); nesse contexto, as vozes se encontram e se mesclam e é esta heterogeneidade que faz com que o sertão surja afirmando a diferença às formas modulares de nação - diferença que resiste e teima em não se enquadrar (ver Chatterjee, 2000, p. 229).

Disse anteriormente que a literatura e o cinema procuram encontrar símbolos da identidade nacional. Como se sabe, existe uma intrínseca associação entre língua, literatura - e cinema -, cultura 
e território na constituição da nação como um todo homogêneo, denunciando a cumplicidade existente entre ficção e ordem geopolítica (ver Mignolo, 2003). A crítica tem buscado ressaltar esses símbolos de identidade, muitas vezes imputando a um autor o desejo que se encontra alhures. O que estou propondo nesta análise dos desenredos e interteixos de Guimarães e de Glauber é que talvez devêssemos fazer uma inversão que possibilite perceber que a força crítica desses autores não se ancora prioritariamente na afirmação da identidade nacional por meio do sertão, mas na afirmação do sertão como diferença em relação às forças centrais ou hegemônicas da nação.

O sertão de Guimarães e de Glauber, composto desse intricado de vozes, nesses desenredos, nesses interteixos, manifestando a preocupação com o diferido, justapõe, justamente por essa forma de composição, diversas temporalidades, culturas e territórios, que interagem e se reinventam.

\section{Notas}

1 Refiro-me, aqui, principalmente à obra de Bhabha (1990; 1998).

2 O conceito de comunidade imaginada foi elaborado por Benedict Anderson (1989). Para acompanhar a rica discussão sobre a nação, ver, entre outros, Homi Bhabha (1990; 1998), Stuart Hall (1997), Stuart Hall e Paul Du Gay (1996), Partha Chatterjee (2000).

3 Diversos autores analisaram o sertão, entre eles se destacam Lúcia Lippi de Oliveira (1993; 2000, especialmente o capítulo III), Janaína Amado (1995; 1995a), Marcos Schettino (1995), Candice Vidal (1997), Sidney Valadares Pimentel (1997), Mireya Suárez (1998), Albertina Vincentini (1998), Gilmar Arruda (2000).

4 Sobre espaço-tempo pedagógico e performático, ver Homi Bhabha (1998). 
5 Para uma análise de utopias do ponto de vista histórico-antropológico, ver Alicia Barrabas (1987; 1996). Sobre Canudos e as utopias em Glauber, ver José Gatti (1995). Para análise do sertão em Guimarães como a-topia, ver Ettore Fizazzi-Agrò (1998; 2001).

6 A importância da literatura no contexto brasileiro foi analisada por Antonio Candido (1976). Sobre a relação entre o cinema na descrição do Brasil, principalmente abordando a relação entre rural e a cidade, sertão e cidade, ver Jean Claude Bernadet (1980) e Célia Aparecida Ferreira Tolentino (2001). Sobre "missão", ver Nicolau Sevcenko (1983).

7 Utilizarei, alternada e aleatoriamente, tanto a forma abreviada (Grande sertão, Deus e o Diabo) como a completa para identificar o romance e o filme. Por questões de estilo e praticidade, irei me referir, daqui por diante, a Glauber Rocha simplesmente por Glauber, e a Guimarães Rosa por Guimarães.

8 Estou ciente das dificuldades de trabalhar com linguagens diferenciadas como a literatura e o cinema. Devemos estar atentos sobre a passagem de um modo de expressão a outro. A linguagem cinematográfica valese de imagens, de enquadramentos, de planos, de cenários; a literatura se expressa com a palavra quase que exclusivamente, mas as imagens construídas nas narrativas escritas não são diretamente visualizadas, pois deve haver a interação entre, por exemplo, uma paisagem descrita e interpretada por um escritor e a imaginação do leitor. Entretanto, cinema e literatura trabalham com signo, e o material específico do cinema é o objeto ótico e acústico transformado em signo (Jakobson 1970). Cinema e literatura são, portanto, formas narrativas. A diferença de cada discurso não pode estabelecer barreiras que impossibilitem uma interlocução entre cinema e literatura. Como analisar, se concluirmos pelo estabelecimento de tais barreiras, uma obra como Diário de um padre, de Robert Bresson, que intenciona seguir o livro que está “adaptando" página por página? (Bazin 1991, p. 83). Ademais, a interlocução de Deus e o Diabo, Grande sertão e Os sertões, de Euclides da Cunha (1985), se constitui em procedimento habitual para muitos dos que intentam compreender essas obras. Ora aproximando os dois 
primeiros, ora os dois últimos, ou mesmo mesclando-os, as abordagens sempre pressupõem materiais para interlocução. A comparação entre Guimarães, Glauber e Euclides da Cunha pode ser encontrada em, por exemplo, Norma Bahia Pontes (1965) e Adair de Aguiar Neitzel (s/d).

9 Cleusa Rios Passos (2000) trabalha o termo desenredo para sugerir como a linguagem roseana faz interagir tradições e temas, buscando captar momentos da constituição do feminino. A análise frutífera de Rios nos demonstra como desenredar perfaz o campo semântico intertextual da obra de Guimarães Rosa.

10 Termo formulado por Julia Kristeva (1970) para sublinhar a existência de vozes que se atraem e rejeitam num mesmo texto. Tzvetan Todorov (1987), a partir das idéias de Kristeva, utiliza o termo intertextualidade para se referir ao diálogo entre discursos, e a expressão dialogismo para o diálogo entre interlocutores. Tanto em Guimarães quanto em Glauber, esses tipos de diálogos se interpenetram, e fica quase impossível estabelecer divisão tão nítida. Uso, portanto, os termos indistintamente. Os textos backtinianos indicam que a dialogia se refere ao princípio constitutivo da linguagem e dos discursos, e polifonia caracteriza um tipo de texto que explora o dialogismo, deixando as vozes constitutivas serem vistas - e estão em oposição aos textos monológicos que escondem o caráter dialógico de suas constituições. Sobre o assunto ver Angélica Madeira e Mariza Veloso (1999).

11 Ver Nilce Sant'Anna Martins (2001).

12 Inspiro-me, para sustentar essa suposição, na análise de Willi Bolle (2004) - que assevera que Grande sertão seria uma reescrita de Os sertões, de Euclides da Cunha (1985).

13 Conforme análise de Adair de Aguiar Neitzel, no texto encontrado no site http://br.geocities.com/ciberliteratura/literatura/glauber.html

14 Teogrades é aquele que pronuncia palavras divinas, o que anuncia a vontade dos deuses. Ver Bailly (1988, p. 927), citado em Luiz Roncari (2004). Os nomes na obra de Guimarães são discutidos por diversos autores. Além de Luiz Roncari e Walnice Nogueira Galvão (que logo 
adiante ajudará a discutir este assunto), podemos citar, entre outros: Ana Maria Machado (1976), Augusto de Campos (1991), Kathrin H. Rosenfield (1993; 2006).

15 Segundo Nilce Sant'Anna Martins (2001, p. 276), em seu estudo sobre o léxico de Guimarães, interteixo seria o ato de entretecer, entrelaçar. O termo aparece na obra No Urubuquaquá, no Pinhém (1984).

16 As canções são de Sérgio Ricardo e do próprio Glauber Rocha, citadas em Rocha (1965).

17 Para análise de Villa-Lobos, ver Paulo Renato Guerios (2003).

18 Sobre a Canção de Siruiz, ver também Willi Bolle (2004).

19 Roberto Schwarz (1965) faz uma instigante abordagem sobre o monólogo-diálogo em Guimarães.

20 Utilizo de forma bastante livre o termo códice inspirado em Rita Laura Segato (1998). A autora entende códice como um conjunto de motivos que se repetem, em constante intercâmbio, localizados em diversas formas de interação social, nas práticas rituais e na conversação informal. $\mathrm{O}$ códice indica a repetição e consistência de um núcleo de motivos.

\title{
Sertão (backland) and Narration: Guimarães Rosa, Glauber Rocha and their plots
}

\begin{abstract}
This text tries to verify how the nation was constructed in Grande sertão: veredas [The Devil to Pay in the Backlands] by Guimarães Rosa, and Deus e o Diabo na terra do sol [Black God, White Devil] by Glauber Rocha. By analyzing authors as Homi Bhabha, Stuart Hall and Walter Mignolo, the text inquires how these authors had constructed the sertão (backland).
\end{abstract}

Keywords: space, Nation, sertão (backland), literature, cinema. 


\section{Referências bibliográficas}

ALBUQUERQUE Jr. Durval Muniz de. A invenção do Nordeste e outras artes. Recife: FJN, Massangana; São Paulo: Cortez, 2001.

ANDERSON, Benedict. Nação e consciência nacional. São Paulo: Ática, 1989.

AMADO, Janaína. Construindo mitos: a conquista do Oeste no Brasil e nos EUA. In: PIMENTEL, Sidney Valadares; AMADO, Janaína (Orgs.). Passando dos limites.Goiânia: Ed. da UFG, 1995.

. Sertão, Nação. Estudos Históricos, Rio de Janeiro, v. 8, n. 15, 1995 a.

ARRIGUCCI JÚNIOR, Davi. O mundo misturado: romance e experiência em Guimarães Rosa. Novos Estudos Cebrap, São Paulo, n. 40, p. 7-29, 1994.

ARROYO, Leonardo. A cultura popular em Grande sertão: veredas: filiações e sobrevivências tradicionais, algumas vezes eruditas. Rio de Janeiro: José Olympio, INL, 1984.

BAILLY, A. Dictionnaire grec-français. Paris: Hachette, 1988.

BAKHTIN, Mikhail. Estética da criação verbal. São Paulo: Martins Fontes, 1997.

BARRABAS, Alicia. Utopias indias: movimientos sociorreligiosos en México. México: Ed. Grijalbo, 1987.

- Movimientos sociorreligiosos e identidad. In: ZARUR, George (Org.). Etnia e Nação na América Latina. Washington, USA, 1996. V. 1 .

BAZIN, André. O cinema. Rio de Janeiro: Brasiliense, 1991.

BENJAMIN, Walter. A obra de arte na época de suas técnicas de reprodução. In: BENJAMIN, W.; HABERMAS, J.; HORKHEIMER, M.; ANDORNO, T. Textos escolhidos. São Paulo: Abril, 1980. (Coleção os pensadores). 
BENJAMIN, Walter. O narrador. In: BENJAMIN, W.; HABERMAS, J.; HORRHEIMER, M.: ADORNO, T. Textos escolhidos. São Paulo: Abril, 1980. (Os Pensadores).

BERNADET, Jean Claude. A cidade, o campo. In: CINEMA brasileiro: 8 estudos. Rio de Janeiro: Funarte, 1980.

BHABHA, Homi K. DissemiNation: time, narrative, and margins of the modern nation. In: BHABHA, Homi K. (Org.) Nation and narration. New York: Routledge, 1990.

. O local da cultura. Belo Horizonte: Ed. da UFMG, 1998.

BOLLE, Willi. grandesertão.br. São Paulo: Duas Cidades, Ed. 43, 2004.

CAMPOS, Augusto de. Um lance de "dês" do Grande Sertão. In: COUTINHO, Eduardo de Farias (Org.). Guimarães Rosa. Rio de Janeiro: Civilização Brasileira, 1991. (Coleção Fortuna Crítica, 6).

CANDIDO, Antonio. O sertão e mundo. Diálogo, São Paulo, n. 8, 1957. [Republicado com modificações sob o título "O homem dos avessos", no livro Tese e Antítese. São Paulo, Companhia Editora Nacional, 1964].

. Literatura e sociedade. São Paulo: Companhia Editora Nacional, 1976.

CASTRO, Nei Leandro de. Universo e vocabulário do Grande sertão. 2. ed. Rio de Janeiro: Achiamé, 1982.

CHATTERJEE, Partha. Comunidade imaginada por quem? In: BALAKRISHNAN, Gopal; ANDERSON, Benedict (Orgs.). Um mapa da questão nacional. Rio de Janeiro: Contraponto, 2000.

CUNHA, Euclides da. Os sertões: campanha de Canudos. São Paulo: Brasiliense, 1985.

DAS, Veena. Subaltern as perspective. Subaltern Studies, n. 6, p. 310-324, 1989.

DEUS e o diabo na terra do sol [filme]. Direção: Glauber Rocha. Produção: Luis Augusto Mendes. Intérpretes: Geraldo Del Rey, Yoná Maga- 
lhães, Mauricio do Valle, Othon Bastos e outros. Roteiro: Glauber Rocha, Walter Lima Jr. Rio de Janeiro: Copacabana Filmes, 1964. (115 min), son., preto e branco.

DIÁRIO de um padre [filme]. Direção: Robert Bresson. Intérpretes: Claude Laydu, Jean Riveyre, André Guibert, Marie-Monique Arkel e outros. Roteiro: George Bernanos, Robert Bresson. França: Union Général Cinématographique, 1951. (110 min), son., preto e branco.

DUSSEL, Enrique. Eurocentrism and Modernity. In: BEVERLEY, John et al. (Ed.). The postmodernism debate in Latin América. Durham (NC): Duke University Press, 1995.

FINAZZI-AGRÒ, Ettore. A cidade e o deserto: (des)caminhos urbanos no Grande Sertão. In: HARDMAN, Francisco Foot (Org.). Morte e progresso: cultura brasileira como apagamento de rastros. São Paulo: Unesp, 1998.

. Um lugar do tamanho do mundo: tempos e espaços da ficção em João Guimarães Rosa. Belo Horizonte: Ed. UFMG, 2001.

FONSECA, Rubem. Contos reunidos. São Paulo: Companhia das Letras, 1994.

GARDIES, René. Glauber Rocha. Paris: Seghers, 1965.

GALVÃO, Walnice Nogueira. Formas do falso: um estudo sobre a ambigüidade no Grande Sertão: veredas. São Paulo: Perspectiva, 1991.

. Guimarães Rosa. São Paulo: Publifolha, 2000. (Col. Folha Explica).

GATTI, José. Dialogism and syncretism in the films of Glauber Rocha. Dissertation (Doctorate) - University of New York, 1995.

GUERIOS, Paulo Renato. Heitor Villa-Lobos e o ambiente artístico parisiense: convertendo-se em um músico brasileiro. Mana, Estudos de Antropologia Social, Rio de Janeiro, v.9, n.1, p. 81-108, 2003.

HALL, Stuart. Identidades culturais na Pós-Modernidade. Rio de Janeiro: DP\&A, 1997. 
HALL, Stuart. Da diáspora: identidades e mediações culturais. Edição organizada por Liv Sovik. Belo Horizonte: Ed. UFMG, 2003.

HALL, Stuart; DU GAY, Paul. Questions of cultural identity. London: Sage, 1996.

HORA e a vez de Augusto Matraga (A) [filme]. Direção: Roberto Santos. Produção: Luis Carlos Barreto, Roberto Santos, Nelson Pereira dos Santos. Intérpretes: Leonardo Villar, Jofre Soares, Maria Ribeiro, Maurício do Valle e outros. Roteiro: Roberto Santos. [s.l.]: Difilm, L. C. Barreto Produções Cinematográficas, 1965. (109 min), son., preto e branco.

JAKOBSON, Roman. Linguística, poética, cinema. São Paulo: Perspectiva, 1970.

KRISTEVA, Julia. Introduction. In: BAKHTIN, M. La poétique de Dostoievski. Paris, Seuil, 1970.

LIMA, Luiz Costa. Mito e provérbio em Guimarães Rosa. In: . A metamorfose do silêncio. Rio de Janeiro: Eldorado, 1974. p. 49-66.

MACHADO, Ana Maria. Recado do nome: leitura de Guimarães Rosa à luz do nome de seus personagens. Rio de Janeiro: Imago, 1976.

MARTINS, Nilce Sant'Anna. O léxico de Guimarães Rosa. São Paulo: Edusp, 2001.

MIGNOLO, Walter D. Histórias locais, projetos globais: colonialidade, saberes subalternos e pensamento liminar. Belo Horizonte: Ed. UFMG, 2003.

NEITZEL, Adair de Aguiar. Glauber Rocha e Guimarães Rosa: entre Deus e o Diabo (ensaio). [s.d.] Disponível em: <http://br.geocities.com/ ciberliteratura/literatura/glauber.html>. Acesso em: 12 jun. 2007.

NOITES do sertão [filme]. Direção e roteiro: Carlos Alberto Prates Correia. Intérpretes: Cristina Aché, Maria Alves, Sura Berditchevsky e outros. [s.1.]: Cinefilmes, 1984. (100 min), son., color. 
OLIVEIRA, Lúcia Lippi de. Bandeirantes e pioneiros: as fronteiras no Brasil e nos Estados Unidos. Novos Estudos CEBRAP, São Paulo,v. 37, 1993.

OLIVEIRA, Lúcia Lippi de. A conquista do espaço: sertão e fronteira no pensamento brasileiro. In: - Americanos: representações da identidade nacional no Brasil e nos EUA. Belo Horizonte: Ed. da UFMG, 2000.

OUTRAS histórias [filme]. Direção: Pedro Bial. Roteiro: Alcione Araujo, Pedro Bial. Intérpretes: Teuda Bara, Márcia Bechara, Sílvia Buarque, Antônio Calloni e outros. [s.1.]: [s.n.], 1999. (100 min), son., color.

PASSOS, Cleusa Rios. Guimarães Rosa: do feminino e suas estórias. São Paulo: Hucitec, 2000.

PIMENTEL, Sidney Valadares. O chão é o limite: a festa do peão de boiadeiro e a domesticação do sertão. Goiânia: UFG, 1997.

PONTES, Norma Bahia. Aproximações literárias e criação crítica. In: GLAUBER Rocha. Rio de Janeiro: Civilização Brasileira, 1965.

RONCARI, Luiz. O Brasil de Rosa: o amor e o poder. São Paulo: Unesp, 2004.

ROCHA, Glauber. Deus e o Diabo na terra do sol. Rio de Janeiro: Civilização Brasileira, 1965.

ROSA, João Guimarães. Minha gente. In: . Sagarana. Rio de Janeiro: José Olympio, 1974.

. No Urubuquaquá, no Pinhém. In: . Corpo de baile. Rio de Janeiro: Nova Fronteira, 1984. . Tutaméia. In: . Terceiras estórias. Rio de Janeiro: Nova Fronteira, 1985.

. Grande sertão: veredas. Rio de Janeiro: Nova Fronteira, 1986. 
ROSENFIELD, Kathrin H. Os descaminhos do demo: tradição e ruptura em Grande sertão: veredas. São Paulo: Edusp, Imago, 1993.

. Desveredando Rosa: a obra de J. G. Rosa e outros ensaios rosianos. Rio de Janeiro: Topbooks, 2006.

SAGARANA, o duelo [filme]. Direção e roteiro: Paulo Thiago. Intérpretes: Rodolfo Arena, Joel Barcellos, Zózimo Bulbul, Sadi Cabral e outros. Múisica: Tom Jobim. [s.1.]: Paulo Thiago Produções Cinematográficas, 1973. (110 min), son., color.

SCHENTTINO, Marco P. F. Espaços do sertão. Dissertação (Mestrado) - Universidade de Brasília (UnB), 1995.

SEGATO, Rita Laura. The color-blind subject of myth; or, where to find Africa in the Nation. Annual Review of Anthropology, n. 27, p. 12951, 1998.

SCHWARZ, Roberto. Grande sertão: a fala. In: . A sereia e o desconfiado: ensaios críticos. Rio de Janeiro: Civilização Brasileira, 1965. p. 23-27.

SEVCENKO, Nicolau. Literatura como missão: tensões sociais e criação cultural na 1 ${ }^{a}$. República. São Paulo: Brasiliense, 1983.

SUÁREZ, Mireya. Sertanejo: um personagem mítico. Sociedade e Cultura, Goiânia, v.1, n. 1, p. 29-39, jan./jun. 1998. Disponível em: <http:// www.revistas.ufg.br/index.php/fchf/article/view/1777/2138>.

TERCEIRA margem do rio (A) [filme]. Direção e roteiro: Nelson Pereira dos Santos. Intérpretes: Lavoisier Albernaz, Denise Alvarez, Bárbara Brandt, Afonso Brazza e outros. [Paris]: Centre Nacional du Cinéma, Regina Filmes, 1994. (98 min), son., color.

TODOROV, T. (Org.). Teoria da literatura: textos dos formalistas russos apresentados por Tzvetan Todorov. Lisboa: Edições 70, 1987. 2 v.

TOLENTINO, Célia Aparecida Ferreira. O rural no cinema brasileiro. São Paulo: Unesp, 2001. 
VAN GENNEP, Arnauld. Ritos de passagem. Petrópolis: Vozes, 1978.

VELOSO, Marisa; MADEIRA, Angélica. Leituras brasileiras. itinerários no pensamento social e na literatura. São Paulo: Paz e Terra, 1999.

VICENTINI, Albertina. O sertão e a literatura. Sociedade e Cultura, Goiânia, v. 1, n. 1, p. 41-54, jan./jun. 1998. Disponível em: <http://www. revistas.ufg.br/index.php/fchf/article/view/1778/2139>.

VIDAL, Candice. A pátria geográfica: sertão e litoral no pensamento social brasileiro. Goiânia, Ed. da UFG, 1997.

XAVIER, Ismail. Sertão mar: Glauber Rocha e a estética da fome. São Paulo: Ed. Brasiliense, 1983. 